\title{
Microendoscopic decompression for cervical spondylotic myelopathy
}

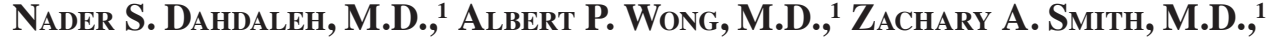 \\ Ricky H. Wong, M.D., ${ }^{2}$ Sandi K. Lam, M.D., ${ }^{2}$ and Richard G. Fessler, M.D., Ph.D. ${ }^{1}$ \\ ${ }^{1}$ Department of Neurological Surgery, Northwestern University Feinberg School of Medicine, Chicago; and \\ ${ }^{2}$ Department of Neurological Surgery, University of Chicago, Illinois
}

\begin{abstract}
Object. Cervical spondylotic myelopathy (CSM) is a common cervical degenerative disease that affects the elderly population. Spinal cord decompression is achieved through various anterior and posterior approaches including anterior cervical decompression and fusion, laminectomy, laminoplasty, and combined approaches. The authors describe another option, minimally invasive endoscopically assisted decompression of stenosis (MEDS), which obviates the need for muscle dissection and disruption of the posterior tension band, a cause of postlaminectomy kyphosis.

Methods. The authors conducted a retrospective study of 10 patients with CSM who underwent MEDS from January 2002 through July 2012. Data were collected on demographics, preoperative and postoperative Nurick scores, postoperative Odom scores, and preoperative and postoperative Cobb angles.

Results. The mean patient age $( \pm \mathrm{SD})$ was $67 \pm 7.7$ years; 8 patients were male. The average number of disc levels operated on was 2.2 (range $1-4$ ). The mean Nurick score was $1.6 \pm 0.7$ preoperatively and improved to $0.3 \pm$ 0.7 postoperatively $(\mathrm{p}<0.0005)$. The postoperative Odom scores indicated excellent outcomes for 4 patients, good for 3 , fair for 2 , and poor for 1 . The average preoperative focal Cobb angle at the disc levels operated on was $-0.43^{\circ}$ $\pm 1.9^{\circ}$. The average Cobb angle at the last follow-up visit was $0.25^{\circ} \pm 1.6^{\circ}(\mathrm{p}=0.6)$. The average follow-up time was $18.9 \pm 32.1$ months. There were no intraoperative or postoperative complications.

Conclusions. For selected patients with CSM, whose pathologic changes are primarily posterior and who have acceptable preoperative lordosis, MEDS is an alternative to open laminectomy and laminoplasty. (http://thejns.org/doi/abs/10.3171/2013.3.FOCUS135)
\end{abstract}

\begin{abstract}
KEY WORDS - cervical spondylotic myelopathy • minimally invasive decompression microendoscopic decompression
\end{abstract}

A MONG elderly persons, CSM is the most common cervical spinal cord disorder. ${ }^{8}$ These patients often experience gait dystaxia and problems with fine motor skills and dexterity. They might also have signs reflecting upper motor neuron disease. ${ }^{8}$ Although intervention is controversial during the early stages of the disease when symptoms are absent or minimal, ${ }^{21}$ surgical intervention is often pursued as symptoms progress. . $^{5,19,24}$

The goal of surgical intervention is primarily spinal cord decompression. If the patient has coexisting kyphotic deformity or instability, fusion is also required. Decompression is achieved through anterior, posterior, or combined approaches. Anterior approaches include anterior cervical discectomy and corpectomies ${ }^{13,20}$ posterior approaches involve laminectomies with or without fusions and laminoplasties. . $^{9,14,22,24}$

\footnotetext{
Abbreviations used in this paper: $\mathrm{CSM}=$ cervical spondylotic myelopathy; MEDS = minimally invasive endoscopically assisted decompression of stenosis.
}

Multilevel laminectomies are associated with increased risk for postlaminectomy kyphosis ${ }^{10,24}(6 \%-47 \%)$ because of the potential destabilizing effects after removal of the spinous process and the supraspinous and interspinous ligaments (posterior tension band) during the laminectomy. Laminoplasty minimizes the amount of posterior tension band removed and, hence, minimizes the risk for postoperative kyphosis. The comparative outcomes, however, are still a matter of controversy. ${ }^{14}$

Minimally invasive techniques for operating on the spine have evolved; the goal is to achieve the same outcomes as open surgeries but through smaller incisions and, more importantly, with less muscle dissection. Avoiding muscle trauma and devascularization lowers rates of wound infections, blood loss, postoperative pain, and hospitalization time. ${ }^{3}$ We have used a minimally invasive technique to treat certain cases of cervical spondylotic myelopathy. The patients are primarily those who have acceptable preoperative effective cervical lordosis, ${ }^{6}$ whose preoperative flexion-extension radiographs do not indicate abnor- 
mal motion, and whose radiographs do not show segmental listhesis. The technique involves a unilateral paramedian approach through small incisions, with minimal muscle dissection, through which decompressive single or multilevel bilateral hemilaminotomies are achieved with total preservation of the posterior tension band.

\section{Methods}

\section{Data Collection}

After obtaining institutional review board approval from Northwestern University and the University of Chicago, we retrospectively reviewed the charts and radiographs of 10 patients who had undergone MEDS for CSM from January 2002 through July 2012. These patients were identified among 248 patients with CSM who had been treated with other approaches during the same time. Outcomes were measured by using preoperative and postoperative Nurick scores and postoperative Odom scores and comparing preoperative and postoperative Cobb angle measurements at the levels operated on. The angle was measured between the superior endplate of the rostrally decompressed level and the inferior endplate of the caudally decompressed level. We used this technique primarily for patients without preoperative cervical kyphosis (neutral or lordotic), indicated by their effective cervical lordosis. ${ }^{6}$

\section{Statistical Analyses}

Data are expressed as the mean $\pm \mathrm{SD}$; categorical variation is expressed as a percentage. Statistical analyses were performed by using the standard Student t-test (Microsoft Excel 2010) when appropriate.

\section{Surgical Technique}

After the patient has been intubated and general anesthesia has been induced, the patient is placed in a 3 -point pin Mayfield headrest and positioned sitting. With fluoroscopic guidance, a $2.0-$ to $2.5-\mathrm{cm}$ incision is then marked $1.5 \mathrm{~cm}$ lateral to the midline at the level of interest. After the incision is made, the fascia is incised under direct vision. Dissection to the lateral mass/facet is then performed by using Metz scissors under fluoroscopic guidance. This dissection enables easy, tension-free insertion of sequential dilators to dilate the paraspinal muscles, docking at the facet at all times. An appropriately sized working channel is introduced and attached to an extension arm attached to the table. The working channel (tubular retractor) (Fig. 1) is then angled at about $30^{\circ}$ medially, and the dilators are removed (Fig. 2). The endoscope is then introduced and fixed to the working channel.

The rest of the operation is conducted while looking at the magnified endoscopic image on the monitor. The remaining soft tissue is dissected with monopolar or bipolar cautery. Care must be taken medially to avoid entering the spinal canal through the interlaminar space. An angled curette is then used to define the cephalad and caudal sublaminar space. The ipsilateral hemilaminectomy is then begun by using $1-\mathrm{mm}$ or $2-\mathrm{mm}$ Kerrison

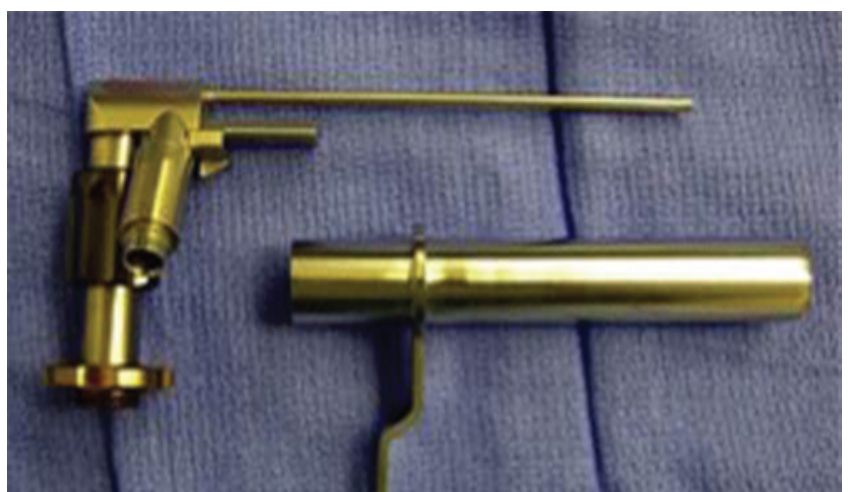

FIG. 1. Endoscopic tubular retractor system.

rongeurs and is extended into a foraminotomy and medial facetectomy by using a drill and Kerrison rongeurs. Whenever possible, the ligamentum flavum is kept intact to help protect the dura. The working channel is then angled to the contralateral side, and contralateral decompression is achieved by drilling the base of the spinous process and ventral surface of the contralateral lamina to the contralateral pedicle. The ligamentum flavum can then be removed. Care is taken to not put any pressure whatsoever on the thecal sac during drilling and decompression (Figs. 3 and 4).

Further decompression at other levels is conducted by angulating the working channel cranially or caudally as needed. After achieving hemostasis, the working channel is removed carefully and the fascia is approximated. The subcutaneous layer is then approximated, the skin is sutured in a subcuticular fashion, and skin glue (Dermabond, Johnson \& Johnson) is applied.

\section{Results}

Among the 10 patients, the mean age was $67 \pm 7.7$

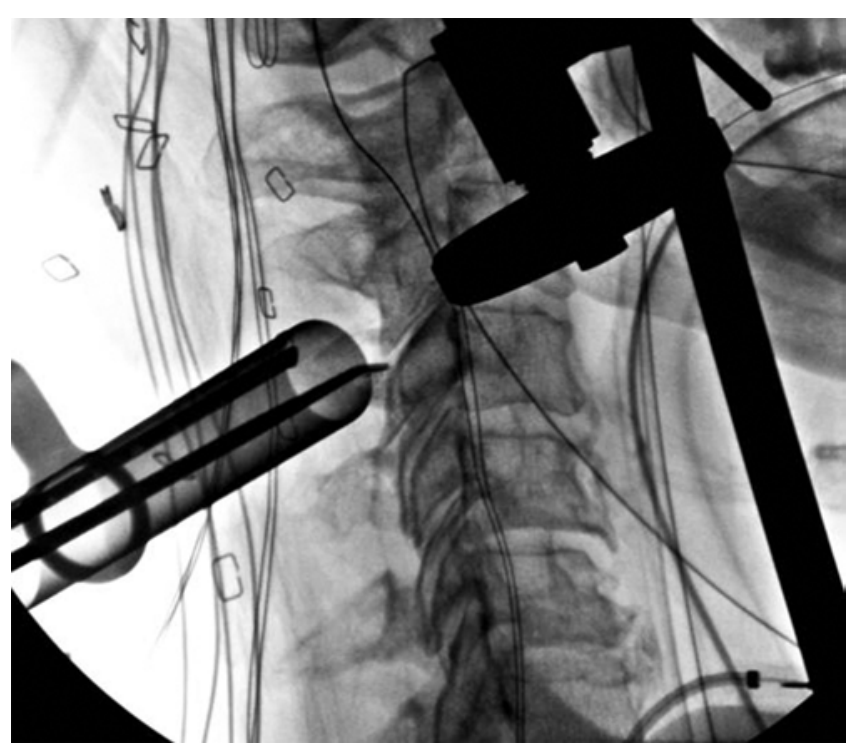

FIG. 2. Intraoperative lateral radiograph of the cervical spine showing placement of the tubular retractor on the area of interest angled at about $30^{\circ}$ to $45^{\circ}$ to achieve ipsilateral and contralateral spinal cord decompression. 


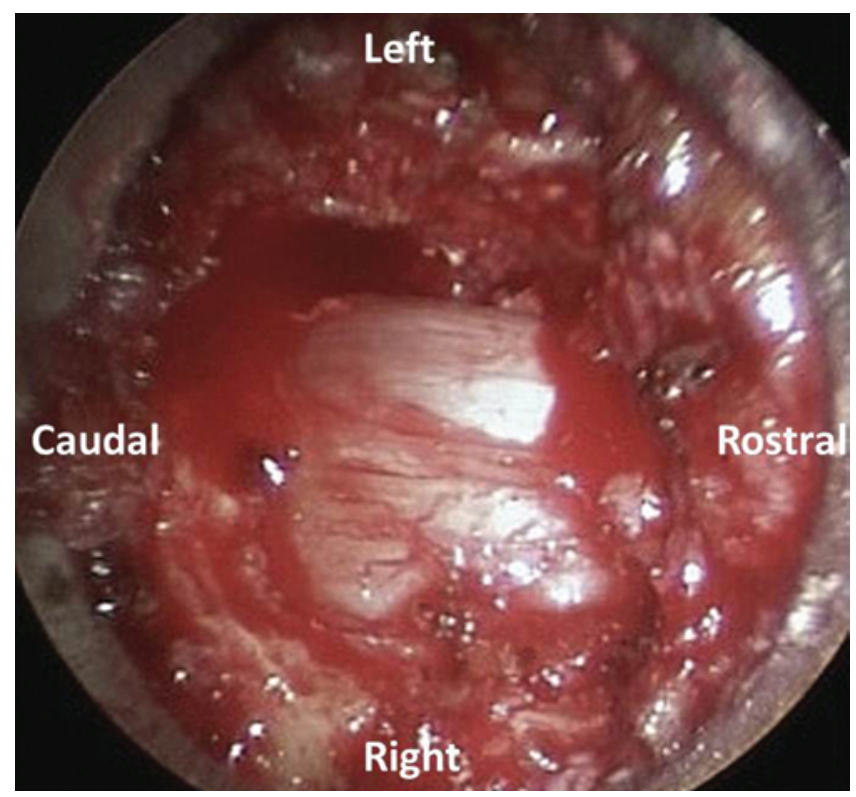

Fig. 3. Intraoperative endoscopic view of the spinal cord after bilateral decompression.

years, 8 were male, and 4 had radiculopathy in addition to myelopathy and received foraminotomies at the corresponding symptomatic levels. The average disc level operated on was 2.2 (range 1-4) (Table 1). The mean Nurick score was $1.6 \pm 0.7$ preoperatively and improved to 0.3 \pm 0.7 postoperatively $(\mathrm{p}=0.0005)$. Postoperative Odom scores indicated excellent outcomes for 4 patients, good outcomes for 3 , fair outcomes for 2 , and poor outcome for 1. Radiographically, the mean preoperative focal Cobb angle at the disc level operated on was $-0.43^{\circ} \pm 1.9^{\circ}$. The mean Cobb angle at the last follow-up visit was $0.25^{\circ} \pm$
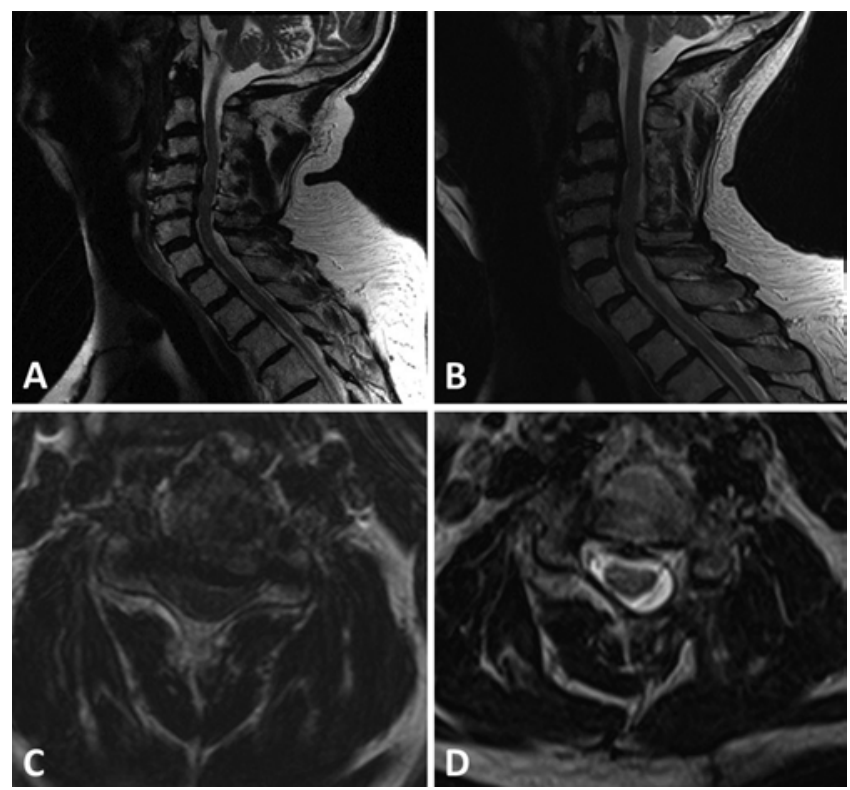

FIG. 4. Preoperative T2-weighted sagittal (A) and axial (C) MR images of the cervical spine demonstrating stenosis at C3-4 and C4-5. Postoperative T2-weighted sagittal MR image (B) demonstrating decompression after MEDS. Note that the left-sided approach for the decompression as the contralateral lamina is preserved (D).
TABLE 1: Patient characteristics

\begin{tabular}{lc}
\hline \multicolumn{1}{c}{ Characteristic } & Value \\
\hline age in yrs* & $67 \pm 7.7$ \\
$\%$ male & 80 \\
disc level operated on* & $2.2 \pm 0.9$ \\
blood loss $(\mathrm{ml})^{*}$ & $32.3 \pm 12.5$ \\
hospitalization in days & $1.6 \pm 0.5$ \\
\hline
\end{tabular}

* Values are presented as the mean \pm SD.

$1.6^{\circ}(\mathrm{p}=0.6)$ (Table 2). The mean blood loss was 32.3 $\pm 12.5 \mathrm{ml}$, and the mean hospitalization time was $1.6 \pm$ 0.5 days. The average follow-up time for the patients was $18.9 \pm 32.1$ months. None of the 10 patients experienced intraoperative or postoperative complications.

\section{Discussion}

While achieving the same goals of traditional open surgeries, minimally invasive surgery techniques obviate stripping and dissection of the paraspinal muscles. ${ }^{3}$ This avoidance of muscle trauma, atrophy, and ischemia leads to faster patient recovery, less intraoperative blood loss, lower rates of postoperative wound infections, and lower cost, ${ }^{2,11,16,17,23}$ as has been demonstrated by multiple studies, especially in the lumbar spine. For treatment of cervical radiculopathy, minimally invasive laminoforaminotomy via microscope or endoscope has been gaining popularity..$^{4,18}$

Cervical spondylotic myelopathy is an increasingly prevalent problem that affects elderly persons. In patients with spondylotic changes, spinal cord compression results from disc osteophyte spurs anteriorly, hypertrophied facets, and thickening of the ligamentum flavum posteriorly? Regardless whether fusions are performed, decompression has been included as part of the surgical strategy. Laminectomies, especially at multiple levels, have been associated with development of postoperative kyphosis, which adversely affects outcomes. Efforts to avoid this outcome include supplemental fusion or laminoplasty (a technique in which the posterior tension band is not disrupted).

We propose an alternative minimally invasive technique, MEDS, which avoids the resection and disruption of the spinous process and the interspinous and supraspinous ligaments (the posterior tension band). This technique should decrease the chances of postlaminectomy kyphosis, especially after multilevel decompression. This technique also obviates the need for posterior fusion and

TABLE 2: Clinical and radiographic outcomes

\begin{tabular}{cccc}
\hline & \multicolumn{2}{c}{ Measurement (mean \pm SD) } & \\
\cline { 2 - 3 } Outcome & Preop & \multicolumn{1}{c}{ Postop } & p Value \\
\hline Nurick score & $1.6 \pm 0.7$ & $0.3 \pm 0.7$ & 0.0005 \\
Cobb angle* $^{*}$ & $-0.43^{\circ} \pm 1.9^{\circ}$ & $0.25^{\circ} \pm 1.6^{\circ}$ & 0.6 \\
\hline
\end{tabular}

* At levels operated on. Negative value reflects lordotic angle. 
the resultant loss of motion and risk for adjacent segment degeneration and disease. ${ }^{25}$

In CSM patients who have appropriate effective cervical lordosis and no abnormal motion (according to dynamic preoperative imaging), decompression can be technically successful through MEDS. To date only 1 study, conducted by Minamide et al.,$^{12}$ has explored the clinical outcomes of microendoscopic decompression surgery for cervical myelopathy. Their retrospective study analyzed 51 patients who underwent MEDS for CSM. The average patient age was 62.9 years, and average followup time was 20.3 months. The outcome measures were Japanese Orthopaedic Association scores, 36-Item Short Form Health Survey responses, and visual analog scale scores for axial pain. The Japanese Orthopaedic Association score was 10.1 preoperatively and improved to 13.6 postoperatively. All 36-Item Short Form Survey subcategories improved postoperatively. The visual analog scale score was 46 preoperatively and improved to 15 postoperatively. Radiographically, the average lordotic Cobb angle at the levels operated on was $6.7^{\circ}$ preoperatively and remained the same at the last follow-up visit. Among the 51 patients, 4 complications occurred: 1 dural tear that was repaired intraoperatively, 2 postoperative C-5 palsies, and 1 compressive epidural hematoma that caused quadriparesis and required operative evacuation. The average hospital stay for the 51 patients was 8.6 days.

We demonstrated similar improved outcomes, on average, for the $10 \mathrm{CSM}$ patients in our study. No postoperative worsening of the Cobb angle occurred, no complications occurred, and all patients were discharged within 48 hours.

Additionally, MEDS enables performance of foraminotomies, through the same working channel, for patients with mixed myelopathy and radiculopathy symptoms. The destabilizing effect of adding a foraminotomy to the partial laminectomy during MEDS is less than that of performing a foraminotomy after a total laminectomy during an open procedure ${ }^{26}$ (unpublished data from finite element modeling studies). Biomechanical finite element modeling studies have demonstrated that motion in the lumbar spine during flexion, extension, and right and left axial rotation is increased more after traditional laminectomy than after minimally invasive laminectomy. ${ }^{1,15} \mathrm{An}$ other advantage of MEDS is its ability to be performed at noncontiguous levels with smaller incisions and without unnecessary muscle dissection and exposures.

Of note, although MEDS carries the benefits of other minimally invasive techniques and avoids disruption of the posterior tension band, it is applicable to only certain CSM patients: those who have acceptable cervical lordosis, those for whom dynamic imaging does not indicate instability, and those who do not have segmental listheses. For patients who have primarily anterior pathologic changes, kyphotic deformities, or instability, other corrective or reconstructive instrumented techniques (anterior, posterior, or a combination) should be pursued. This selection process is reflected by the fact that only 10 of the 248 patients treated for cervical spondylotic myelopathy over 10 years were candidates for MEDS. This paper should be carefully interpreted as describing a new technique for carefully selected patients with CSM. Future studies comparing this technique with other dorsalapproach surgeries for CSM, such as laminectomies and laminoplasties, should provide more substantial evidence of efficacy if better and validated outcome measures (such as the Neck Disability Index and modified Japanese Orthopaedic Association scores) are used.

\section{Conclusions}

MEDS can be used instead of open laminectomy and laminoplasty for CSM patients with acceptable preoperative lordosis and no abnormal motion. More definitive comparative studies are needed to demonstrate the efficacy and complication profiles of MEDS, open dorsal decompressions, and laminoplasty procedures for treatment of CSM.

\section{Disclosure}

Dr. Fessler receives royalties from Medtronic.

Author contributions to the study and manuscript preparation include the following. Conception and design: Fessler, Dahdaleh, AP Wong, Smith. Acquisition of data: Dahdaleh, AP Wong, Smith, RH Wong, Lam. Analysis and interpretation of data: all authors. Drafting the article: all authors. Critically revising the article: all authors. Reviewed submitted version of manuscript: Fessler, Dahdaleh, AP Wong, Smith, Lam. Approved the final version of the manuscript on behalf of all authors: Fessler. Statistical analysis: Dahdaleh, Lam. Administrative/technical/material support: Dahdaleh.

\section{References}

1. Bresnahan L, Ogden AT, Natarajan RN, Fessler RG: A biomechanical evaluation of graded posterior element removal for treatment of lumbar stenosis: comparison of a minimally invasive approach with two standard laminectomy techniques. Spine (Phila Pa 1976) 34:17-23, 2009

2. Cahill KS, Levi AD, Cummock MD, Liao W, Wang MY: A comparison of acute hospital charges after tubular versus open microdiskectomy. World Neurosurg [epub ahead of print], 2012

3. Fessler RG, O'Toole JE, Eichholz KM, Perez-Cruet MJ: The development of minimally invasive spine surgery. Neurosurg Clin N Am 17:401-409, 2006

4. Gala VC, O’Toole JE, Voyadzis JM, Fessler RG: Posterior minimally invasive approaches for the cervical spine. Orthop Clin North Am 38:339-349, abstract v, 2007

5. Ghogawala Z, Martin B, Benzel EC, Dziura J, Magge SN, Abbed KM, et al: Comparative effectiveness of ventral vs dorsal surgery for cervical spondylotic myelopathy. Neurosurgery 68:622-631, 2011

6. Gwinn DE, Iannotti CA, Benzel EC, Steinmetz MP: Effective lordosis: analysis of sagittal spinal canal alignment in cervical spondylotic myelopathy. Clinical article. J Neurosurg Spine 11:667-672, 2009

7. Henderson FC, Geddes JF, Vaccaro AR, Woodard E, Berry KJ, Benzel EC: Stretch-associated injury in cervical spondylotic myelopathy: new concept and review. Neurosurgery 56:1101-1113, 2005

8. Klineberg E: Cervical spondylotic myelopathy: a review of the evidence. Orthop Clin North Am 41:193-202, 2010

9. Manzano GR, Casella G, Wang MY, Vanni S, Levi AD: A prospective, randomized trial comparing expansile cervical laminoplasty versus cervical laminectomy and fusion for multilevel cervical myelopathy. Neurosurgery 70:264-277, 2011

10. McAllister BD, Rebholz BJ, Wang JC: Is posterior fusion nec- 


\section{Microendoscopic decompression for CSM}

essary with laminectomy in the cervical spine? Surg Neurol Int 3 (Suppl 3):S225-S231, 2012

11. McGirt MJ, Parker SL, Lerner J, Engelhart L, Knight T, Wang MY: Comparative analysis of perioperative surgical site infection after minimally invasive versus open posterior/transforaminal lumbar interbody fusion: analysis of hospital billing and discharge data from 5170 patients. Clinical article. J Neurosurg Spine 14:771-778, 2011

12. Minamide A, Yoshida M, Yamada H, Nakagawa Y, Maio $\mathrm{K}$, Kawai M, et al: Clinical outcomes of microendoscopic decompression surgery for cervical myelopathy. Eur Spine J 19:487-493, 2010

13. Naderi S, Alberstone CD, Rupp FW, Benzel EC, Baldwin NG: Cervical spondylotic myelopathy treated with corpectomy: technique and results in 44 patients. Neurosurg Focus 1(16): e5, 1996

14. Nurboja B, Kachramanoglou C, Choi D: Cervical laminectomy vs laminoplasty: is there a difference in outcome and postoperative pain? Neurosurgery 70:965-970, 2012

15. Ogden AT, Bresnahan L, Smith JS, Natarajan R, Fessler RG: Biomechanical comparison of traditional and minimally invasive intradural tumor exposures using finite element analysis. Clin Biomech (Bristol, Avon) 24:143-147, 2009

16. O’Toole JE, Eichholz KM, Fessler RG: Surgical site infection rates after minimally invasive spinal surgery. Clinical article. J Neurosurg Spine 11:471-476, 2009

17. Parker SL, Adogwa O, Witham TF, Aaronson OS, Cheng J, McGirt MJ: Post-operative infection after minimally invasive versus open transforaminal lumbar interbody fusion (TLIF): literature review and cost analysis. Minim Invasive Neurosurg 54:33-37, 2011

18. Santiago P, Fessler RG: Minimally invasive surgery for the management of cervical spondylosis. Neurosurgery 60 (1 Supp1 1):S160-S165, 2007

19. Scheufler KM, Kirsch E: Percutaneous multilevel decompressive laminectomy, foraminotomy, and instrumented fusion for cervical spondylotic radiculopathy and myelopathy: as- sessment of feasibility and surgical technique. J Neurosurg Spine 7:514-520, 2007

20. Song KJ, Lee KB, Song JH: Efficacy of multilevel anterior cervical discectomy and fusion versus corpectomy and fusion for multilevel cervical spondylotic myelopathy: a minimum 5-year follow-up study. Eur Spine J 21:1551-1557, 2012

21. Sumi M, Miyamoto H, Suzuki T, Kaneyama S, Kanatani T, Uno K: Prospective cohort study of mild cervical spondylotic myelopathy without surgical treatment. Clinical article. J Neurosurg Spine 16:8-14, 2012

22. Uchida K, Nakajima H, Sato R, Yayama T, Mwaka ES, Kobayashi S, et al: Cervical spondylotic myelopathy associated with kyphosis or sagittal sigmoid alignment: outcome after anterior or posterior decompression. Clinical article. J Neurosurg Spine 11:521-528, 2009

23. Wang MY: Percutaneous thoracolumbar pedicle screw fixation: is it time to revisit spinal fracture treatment? World Neurosurg 74:570-571, 2010

24. Wiggins GC, Shaffrey CI: Dorsal surgery for myelopathy and myeloradiculopathy. Neurosurgery 60 (1 Supp1 1):S71-S81, 2007

25. Xia XP, Chen HL, Cheng HB: Prevalence of adjacent segment degeneration after spine surgery: a systematic review and metaanalysis. Spine (Phila Pa 1976) 38:597-608, 2013

26. Zdeblick TA, Zou D, Warden KE, McCabe R, Kunz D, Vanderby R: Cervical stability after foraminotomy. A biomechanical in vitro analysis. J Bone Joint Surg Am 74:22-27, 1992

Manuscript submitted January 5, 2013.

Accepted March 4, 2013.

Please include this information when citing this paper: DOI: 10.3171/2013.3.FOCUS135.

Address correspondence to: Richard G. Fessler, M.D., Ph.D., Department of Neurological Surgery, Northwestern University Feinberg School of Medicine, Chicago, IL 60611. email: rfessler@ nmff.org. 